1 University of Vale do Paraiba, Sao Jose dos Campos, Brazil

${ }^{2}$ Graduate Program in Dentistry, Federal University of Pelotas, Pelotas, Brazil

${ }^{3}$ University of Taubate, Taubate, Brazil

4 Department of Preventive and Community Dentistry, The University of lowa College of Dentistry and Dental Clinics

Corresponding author:

Mateus Bertolini Fernandes dos Santos

School of Dentistry, Federal University of Pelotas, Pelotas, RS, Brazil

457 Gonçalves Chaves street, room 502 , Pelotas, RS, Brazil $96015-560$ Phone: +55 5399349134 mateusbertolini@yahoo.com.br

Received: February 16, 2018 Accepted: November 19, 2018

\section{Dentists' perceptions and barriers to provide oral care for dependent elderly at home, long-term care institutions or hospitals}

\author{
Albano Porto Cunha $\mathrm{Jr}^{1}$, Mateus Bertolini Fernandes \\ dos Santos ${ }^{2 \star}$, Jarbas Francisco Fernandes Santos ${ }^{3}$, \\ Leonardo Marchini ${ }^{4}$
}

Aim: The aim of this study was to assess the perceptions and barriers to providing oral health care for the dependent elderly in unconventional settings as reported by dentists in the State of São Paulo, Brazil. The Brazilian elderly population is rapidly growing, and a larger elderly population implies an increasing number of dependent elderly patients. Therefore, investigating the perceptions and barriers reported by dentists for caring for these patients becomes important. Methods: An online survey was sent by e-mail to dentists of a metropolitan area in the State of São Paulo, Brazil. Results: The response rate was $3.65 \%(n=125)$. Only $14.4 \%$ of respondents offered home care to the elderly. Lack of experience or training (60.7\%) and the small number of home visits (42.9\%), were the main reported barriers to providing care for the dependent elderly. Most of the respondents (82.4\%) agreed that the age of the patient did not influence their decision to provide care, and $96.8 \%$ agreed that delivering care to the elderly could be a rewarding experience. Conclusion: Few respondents offered care to the elderly and some of the most relevant factors considered in the decision to offer care were, experience and training, personal satisfaction and having gerodontology as a stand-alone course during dental school.

Keywords: Geriatric dentistry. Aged. Oral health. Health services accessibility. 


\section{Introduction}

Life expectancy is increasing worldwide and it is estimated that the Brazilian population will increase by a rate of $0.3 \%$ per year over the next four decades, while the Brazilian elderly population is estimated to grow tenfold more, at a rate of $3.2 \%$ per year. From an economic point of view, the elderly population will increase their participation in the so-called economically active population from $11 \%$ in 2005 to $49 \%$ in 2050 , while the school-age population will decrease from $50 \%$ to $29 \%$. The metropolitan region of Vale do Paraíba e Litoral Norte (MRVP) is one of the five metropolitan regions of the state of São Paulo. MRVP is composed of 39 municipalities subdivided into 5 sub-regions. The overall population of the MRVP is 2,430,392 (1.2\% of the total Brazilian population), with $13.5 \%$ being considered elderly (60+ year-old). By 2025 , the estimated share of the elderly population will be $17.5 \%$ for an overall population of $2,573,268^{1,2}$.

This elderly group makes up $10 \%$ of the functionally dependent population and are usually institutionalized or at-home elders presenting with many co-morbidities, polypharmacy and poor oral health ${ }^{3-18}$. The term oral health defined by WHO as "a state of being free from chronic mouth and facial pain, oral and throat cancer, oral infection and sores, periodontal (gum) disease, tooth decay, tooth loss, and other diseases and disorders that limit an individual's capacity in biting, chewing, smiling, speaking, and psychosocial wellbeing ${ }^{\prime \prime 19}$. As so, it should be emphasized that elderly patients may have physical disabilities that result in the lack of manual dexterity or impaired range of motion ${ }^{20}$, which may hinder the oral hygiene of such patients. Considering dependent elderly, these problems are more critical, since the oral health related activities are often outsourced for a nurse or a family member. Also, access to appropriate oral health care is lacking for this vulnerable group, especially in developing countries ${ }^{21}$.

Dentists report many barriers and difficulties to the provision of appropriate oral health care for the dependent elderly. However, this has not been adequately investigated in Brazil and very little is known about the number and characteristics of Brazilian dentists that offer this type of service $7,16,18,21-24$. Among the difficulties, a previous study reported that dentists face different types of difficulties, which varies from the unwillingness toward treatment, problems when communicating to the patients due to communication and cognitive problems as well as in obtaining radiographs and in other diagnostic tests, and physical problems where sometimes these patients are unable to open their mouth or keep it open for long time ${ }^{25}$. The most commonly reported barriers to providing care for the dependent elderly refer to the lack of adequate equipment, low demand, inadequate reimbursement, the need to leave the office and also the inexperience and lack of training for providing this type of care $\mathrm{c}^{7,16,18}$.

There is a crucial need to provide appropriate oral health care to dependent elderly patients and a lack of publications regarding dentists' perceptions about this type of care in Brazil. Thus, the purpose of the present study was to evaluate the barriers and perceptions of professionals regarding the provision of oral health care to the dependent elderly in unconventional settings such as patients' homes, long-term care institutions or geriatric hospitals. 


\section{Materials and methods}

\section{Subjects}

This study was approved by the Ethics and Research Committee of The University of Taubate (CAAE: 51491615.0.0000.5501) and the research has been conducted in full accordance with the World Medical Association Declaration of Helsinki.

An online survey was sent to the Regional Dental Council of the State of São Paulo, who approved and subsequently forwarded the questionnaire to 4,626 dentists of the MRVP by email. The inclusion criteria adopted in this study was to be registered as a professional in the Regional Dental Council of the State of São Paulo. There were no exclusion criteria.

\section{Survey}

The survey was comprised of questions regarding personal and professional information and only the participants who gave written consent were included in the study.

When asked about their perceptions and barriers to providing care for the elderly and reasons for not offering care, dentists could respond using a five or seven-point Likert scale, as reported by Chowdhry et al. ${ }^{7}$. The questions from the Chowdhry et al. ${ }^{7}$ questionnaires were translated to Portuguese and then back translated to English to confirm the accuracy of the translation. It was then tested by 30 volunteer dentists prior to the survey to check for incongruences and after statistical checking it was regarded as having appropriate language translation.

The respondents of such questionnaire were subdivided into different groups according to their answers; Group A - respondents who offered care to the elderly in long-term care institutions, at-home or hospitals; Group B - respondents who discontinued care for the elderly in long-term care institutions, at-home and hospitals; Group C - respondents who did not offer care to the elderly in long term-care institutions, at home or hospitals, but had the intention to do so; and Group D - respondents who have never offered oral health care for the dependent elderly in long-term care institutions, at-home or hospitals and did not intend to do so.

\section{Data analysis}

The seven-item Likert scale questions were scored as follows: totally agree $=1$; agree $=2$; partially agree $=3$; neutral $=4$; partially disagree $=5$; disagree $=6$; totally disagree $=7$. The five-item Likert scale questions were scored as follows: very important $=1$; important $=2$; neutral $=3$; not important $=4$; unimportant $=5$. The answers received were initially tabulated in a Microsoft Excel 2010 spreadsheet. SPSS V17 and Minitab 16 were used for statistical analysis. One-way ANOVA was used to compare the results and all tests were performed considering an alpha level of 0.05 .

\section{Results}

Of the 4,626 invited dentists, 169 responded (response rate of 3.65\%). Forty-four respondents were excluded (one refused to participate, three were not working in the MRVP 
anymore, 10 were pediatric dentists, and 30 were orthodontists), resulting in a final number of 125. These remaining respondents were subdivided into: Group A ( $n=18 ; 14.4 \%)$ - respondents who offered care to the elderly in long-term care institutions, at-home or hospitals; Group B ( $n=21 ; 16.8 \%)$ - respondents who discontinued care for the elderly in long-term care institutions, at-home and hospitals; Group C ( $n=30 ; 34.88 \% 24 \%)$ respondents who did not offer care to the elderly in long term-care institutions, at home or hospitals, but had the intention to do so; Group D ( $n=56 ; 65.12 \% 44.8 \%)$ - respondents who have never offered oral health care for the dependent elderly in long-term care institutions, at-home or hospitals and did not intend to do so (Figure 1).

In regard to the specialties, a statistical difference between groups was observed only in the distribution of the "Patients with special needs" specialty, with a higher prevalence of Group A respondents $(27.8 \%)$ when compared to groups B $(4.8 \% ; p=0.047)$, $C(0.0 \% ; p=0.002)$ and $D(0.0 \% ; p<0.001)$.

In the comparison of dentists' perceptions regarding performing oral health care for the dependent elderly, respondents from all groups had different opinions regarding the question "patient's age did not influence their decision to provide oral health care." (Table 1).

The comparison of responses from dentists in each group, regarding factors that influence their decision to provide oral health care for the dependent elderly, is presented in

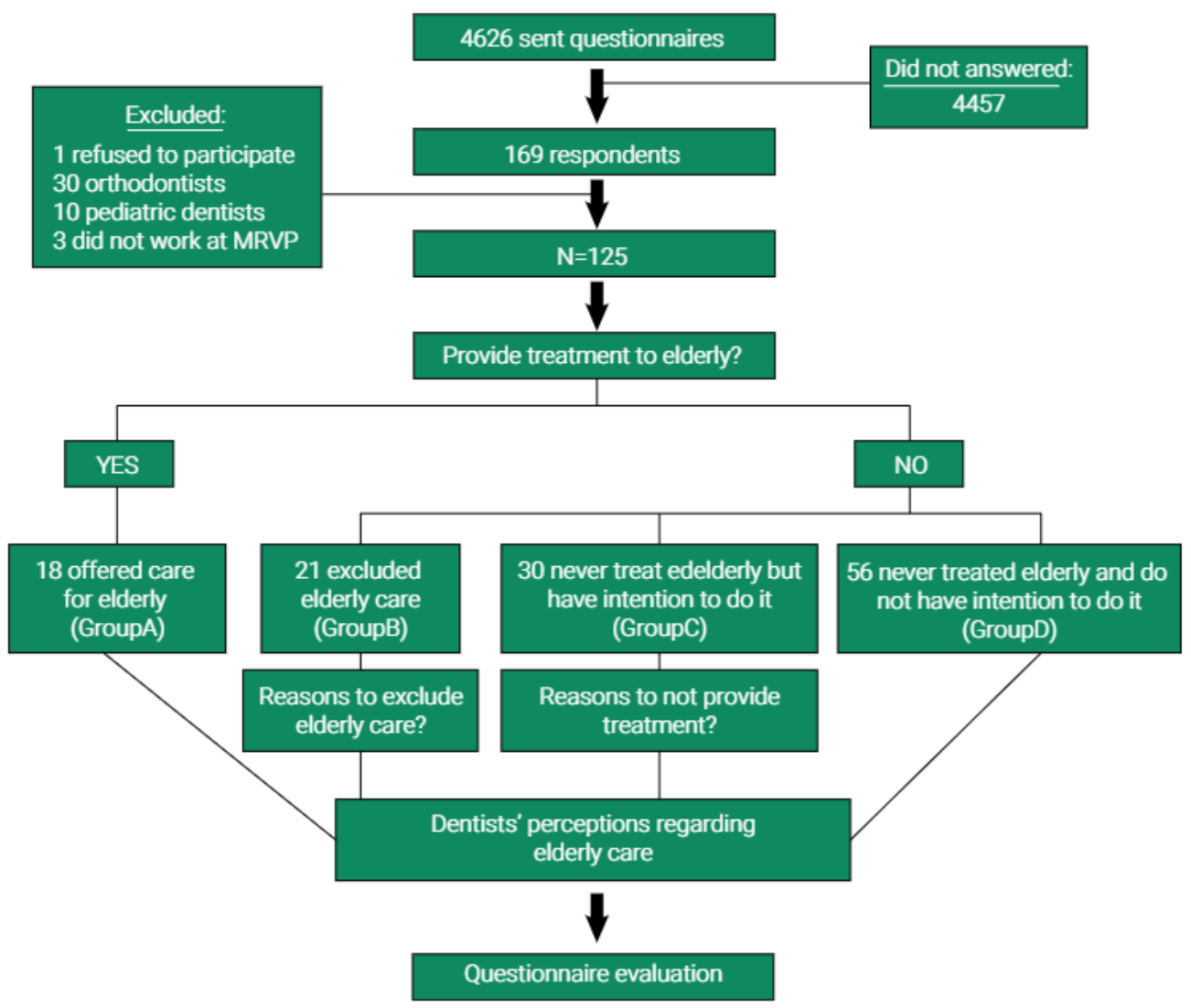

Figure 1. Questionnaire flowchart. 
Table 1. Comparison among groups regarding dentists' reported perceptions of providing oral health care for the dependent elderly. The asterisk (*) indicates statistical significant differences (One-way ANOVA).

\begin{tabular}{lccccc}
\hline & $\begin{array}{c}\text { Group A } \\
(\mathrm{n}=18)\end{array}$ & $\begin{array}{c}\text { Group B } \\
(\mathrm{n}=21)\end{array}$ & $\begin{array}{c}\text { Group C } \\
(\mathrm{n}=30)\end{array}$ & $\begin{array}{c}\text { Group D } \\
(\mathrm{n}=56)\end{array}$ & $\boldsymbol{P}$-value \\
\hline $\begin{array}{l}\text { Treating elderly patients is a } \\
\text { pleasant experience }\end{array}$ & $1.61(0.28)$ & $1.48(0.22)$ & $1.30(0.17)$ & $1.70(0,21)$ & 0.067 \\
\hline $\begin{array}{l}\text { A patient's age does not influence } \\
\text { my decision to provide services }\end{array}$ & $1.39(0.32)$ & $1.90(0.52)$ & $2.63(0.69)$ & $2.41(0,44)$ & $0.037^{\star}$ \\
\hline $\begin{array}{l}\text { Elderly patients rarely follow } \\
\text { recommended treatment }\end{array}$ & $4.50(0.68)$ & $3.86(0.73)$ & $4.67(0.53)$ & $4.11(0,42)$ & 0.236 \\
\hline $\begin{array}{l}\text { It is hard to improve the oral health } \\
\text { of elderly patients }\end{array}$ & $4.00(0.94)$ & $4.57(0.83)$ & $4.47(0.70)$ & $4.07(0,45)$ & 0.602 \\
\hline $\begin{array}{l}\text { Elderly patients present difficulties } \\
\text { because of medical problems or } \\
\text { dementia }\end{array}$ & $4.06(0.85)$ & $3.81(0.84)$ & $3.73(0.65)$ & $3.39(0,43)$ & 0.502 \\
\hline
\end{tabular}

Table 2. Comparison of dentists' responses among groups regarding factors that influence their decision to provide oral health care for the dependent elderly. The asterisk $\left(^{*}\right)$ indicates statistical significant differences (One-way ANOVA).

\begin{tabular}{lccccc}
\hline & $\begin{array}{c}\text { Group A } \\
(\mathrm{n}=18)\end{array}$ & $\begin{array}{c}\text { Group B } \\
(\mathrm{n}=21)\end{array}$ & $\begin{array}{c}\text { Group C } \\
(\mathrm{n}=30)\end{array}$ & $\begin{array}{c}\text { Group D } \\
(\mathrm{n}=56)\end{array}$ & $\boldsymbol{P}$-value \\
\hline Amount of private practice time & $2.00(0.59)$ & $2.19(0.50)$ & $1.53(0.24)$ & $1.86(0.24)$ & 0.112 \\
\hline Amount of personal time & $1.78(0.41)$ & $1.86(0.56)$ & $1.67(0.32)$ & $1.82(0.26)$ & 0.901 \\
\hline Distance to facility & $2.00(0.59)$ & $2.43(0.64)$ & $1.87(0.38)$ & $1.80(0.25)$ & 0.187 \\
\hline Remuneration & $2.50(0.53)$ & $2.24(0.45)$ & $2.17(0.38)$ & $2.00(0.26)$ & 0.349 \\
\hline $\begin{array}{l}\text { Availability of dental operatory and } \\
\text { equipment at facility }\end{array}$ & $1.67(0.48)$ & $1.76(0.38)$ & $1.37(0.22)$ & $1.45(0.21)$ & 0.264 \\
\hline $\begin{array}{l}\text { Personal satisfaction in working with } \\
\text { elderly people }\end{array}$ & $1.39(0.45)$ & $1.19(0.22)$ & $1.17(0.19)$ & $1.32(0.15)$ & 0.542 \\
\hline $\begin{array}{l}\text { Experience and training in treating } \\
\text { elderly people }\end{array}$ & $1.39(0.36)$ & $1.52(0.35)$ & $1.13(0.16)$ & $1.21(0.15)$ & 0.113 \\
\hline
\end{tabular}

Table 2. The responses were based on a five-item Likert scale. The respondents were very homogeneous and the groups tended to consider all seven factors presented as important in the decision to provide oral health care for the dependent elderly, with no differences between them.

Table 3 presents the comparison of dentists' responses among groups, regarding reasons for providing oral health care for dependent elderly, with answers based on a seven-item Likert scale. The reasoning "Part of professional responsibilities" was more relevant for Groups $\mathrm{A}$ and $\mathrm{C}$, with significant statistical differences between Groups $A$ and $D(p=0.006)$ and between Groups $C$ and $D(p=0.002)$. The reasoning "Broadens the scope of my practice" was more relevant for Group $C$ with significant statistical differences between Group B $(p=0.010)$ and Group D $(p=0.008)$.

The groups were homogeneous in agreeing that having the help of dental hygienists and dental assistants, continuing education courses about gerodontology and a gerodontology stand-alone course during dental school had a positive influence on their decision to provide oral health care for the dependent elderly, without significant 
Table 3. Comparison of dentists' responses among groups regarding reasons for providing oral health care for the dependent elderly. The asterisk (*) indicates statistical significant differences (One-way ANOVA).

\begin{tabular}{lccccc}
\hline Reason & $\begin{array}{c}\text { Group A } \\
(\mathrm{n}=18)\end{array}$ & $\begin{array}{c}\text { Group B } \\
(\mathrm{n}=21)\end{array}$ & $\begin{array}{c}\text { Group C } \\
(\mathrm{n}=30)\end{array}$ & $\begin{array}{c}\text { Group D } \\
(\mathrm{n}=56)\end{array}$ & P-value \\
\hline Opportunity to increase my practice & $4.56(0.80)$ & $3.90(0.78)$ & $3.27(0.59)$ & $3.70(0.38)$ & 0.063 \\
\hline $\begin{array}{l}\text { Social contacts with elderly patients } \\
\text { are rewarding }\end{array}$ & $1.94(0.43)$ & $2.00(0.41)$ & $1.83(0.34)$ & $2.25(0.27)$ & 0.268 \\
\hline I want to perform a public service & $3.78(0.96)$ & $4.67(0.77)$ & $3.83(0.67)$ & $4.27(0.43)$ & 0.299 \\
\hline Part of professional responsibilities & $1.67(0.32)$ & $3.00(0.80)$ & $1.57(0.29)$ & $2.96(0.35)$ & $<0.0001^{*}$ \\
\hline Part of semi-retirement practice & $5.06(0.94)$ & $5.52(0.83)$ & $5.03(0.65)$ & $4.88(0.43)$ & 0.576 \\
\hline Broadens the scope of my practice & $3.56(0.83)$ & $3.86(0.83)$ & $2.53(0.45)$ & $3.82(0.39)$ & $0.003^{*}$ \\
\hline $\begin{array}{l}\text { I was asked to work in a long-term } \\
\text { care facility }\end{array}$ & $3.22(1.06)$ & $3.29(0.78)$ & $3.60(0.65)$ & $2.88(0.37)$ & 0.312 \\
\hline $\begin{array}{l}\text { A past patient or family member was } \\
\text { in a long-term care facility }\end{array}$ & $2.33(0.82)$ & $2.33(0.59)$ & $2.20(0.55)$ & $2.14(0.26)$ & 0.925 \\
\hline
\end{tabular}

Table 4. Reasons Group B discontinued the delivery of oral health care for the dependent elderly from their practices and reasons Group D never offered oral health care to the dependent elderly (more than one option could have been selected).

\begin{tabular}{lc}
\hline Reasons $^{\mathrm{a}}$ & $\mathrm{n}^{\circ}(\%)$ \\
\hline For having discontinued dependent elderly care from their practices (Group B) & $\mathbf{2 1 ( 1 0 0 )}$ \\
\hline Lack of demand for services & $9(42.9)$ \\
\hline Loss of leisure time & $6(28.6)$ \\
\hline This type of care do not reach my practice standard of care & $5(23.8)$ \\
\hline Financially unrewarding & $1(4.8)$ \\
\hline Increasing commitments to private office practice & $1(4.8)$ \\
\hline difficulties in management of patients & $0(0)$ \\
\hline Never having offered oral health care to dependent elderly (Group D) & $\mathbf{5 6 ( 1 0 0 )}$ \\
\hline Inadequate training and experience & $34(60.7)$ \\
\hline I have not been asked by residents, administrators or family & $32(57.1)$ \\
\hline I do not have adequate equipment & $22(39.3)$ \\
\hline Too busy in private practice & $17(30.4)$ \\
\hline Lack of appropriate treatment facilities & $15(26.8)$ \\
\hline Financially costly and unrewarding & $6(10.7)$ \\
\hline Bureaucratic barriers would hinder proper treatment of patients & $4(7.1)$ \\
\hline Administrative difficulties in management of patients & $2(3.6)$ \\
\hline
\end{tabular}

differences among groups. Increased bureaucracy, in terms of informed consent or other documents, negatively influenced their decision to provide oral health care for the dependent elderly, and it was more relevant for Group C compared to Group B (One-way ANOVAp=0.027).

The main reasons cited by dentists from groups $B$ and $D$ for discontinuing the delivery of oral health care for the dependent elderly from their practices and for never having offered oral health care for the dependent elderly, respectively, are shown in Table 4. 


\section{Discussion}

The purpose of the present study was to evaluate the barriers and perceptions of professionals regarding the provision of oral health care to the dependent elderly in unconventional settings such as patients' homes, long-term care institutions or geriatric hospitals. It was found that experience and training, personal satisfaction and having gerodontology as a stand-alone course during dental school were among the most relevant factors taken on count by the dentists.

The proportion of respondents who offered care to the dependent elderly in long-term care institutions in the present study was similar to those shown by Chowdhry et al. ${ }^{7}$, in which $14.7 \%$ of respondents offered care, $20.6 \%$ had stopped treatment and $71.2 \%$ had never treated such patients. Our results are also similar to those presented by Moreira et al. ${ }^{21}$, in which $73.4 \%$ of respondents did not treat the elderly, confirming that relatively few dentists decide to treat elderly patients. In the study by Watkins et al. ${ }^{22}$, when asked about providing care for dependent patients at home, $85 \%$ of dentists stated that they did not perform this service and $85 \%$ of the respondents evaluated by Stevens et al. ${ }^{26}$ stated that home care patients should be sent to health centers. In the results from Bots-VantSpijker et al. ${ }^{18}, 42 \%$ of the respondents were not willing to provide oral health care for dependent elderly patients. In the study performed by Sweeney et al. ${ }^{27}, 67 \%$ reported providing some home care, most of whom were community dentistry officers and those working in both urban and rural areas. This contrasts with the findings of this study in which only $14.4 \%$ of respondents provided care for the elderly. Hally et al. ${ }^{28}$ reported that among dentists who provided care for the elderly, $78 \%$ reported being willing to travel $10+$ miles $(16+\mathrm{km})$ to see a patient.

In the present study, groups $C$ and $D$, which did not have offered treatment for dependent elderly, presented a different opinion to the groups $A$ and $B$ when asked if the patient's age influence their decision to provide oral health care to the dependent elderly. Although no statistical difference was observed, the respondents tended to be more neutral for the item "Elderly patients rarely follow recommended treatment", wich was reported by previous findings ${ }^{7}$. Chowdhry et al. ${ }^{7}$ reported that the respondents considered the personal time available, the remuneration and distance of the place of care as the more important factors and that personal satisfaction was less important. Bots-VantSpijker et al. ${ }^{18}$, and Watkins et al. ${ }^{22}$ also cited experience and training for this type of care as a relevant factor influencing respondents intent on providing oral health care to the dependent elderly.

In the study by Chowdhry et al. ${ }^{7}$, respondents agreed that having more appointments (thus avoiding empty-chair time), the opportunity to diversify the type of care and the request for this type of care were the most relevant reasons for providing oral health care to the dependent elderly. In our study, the most cited reasons for providing this type of oral health care were, "Part of professional responsibilities", "A past patient or family member was in a long-term care facility" and "Treating elderly patients is a pleasant experience ".

Respondents of our study reported that having gerodontology as a stand-alone course during dental school positively influenced their decision to provide oral health care for the dependent elderly. These results are in agreement with those of Watkins et al. ${ }^{22}$, 
in which attending courses about the provision of services to the dependent elderly, having gerodontology training in dental school and having clinical training in gerodontology were all strongly associated with the decision to provide oral health care for the dependent elderly.

The most frequent barriers reported by dentists who do not deliver oral health care to the dependent elderly were, "[Lack of] Experience and training in treating elderly people", "I have not been asked by residents, administrators or family", "[Lack of] Availability of a dental operatory and equipment at facility", and "Lack of demand for services". Chowdhry et al. ${ }^{7}$ reported "Treating elderly patients is financially unrewarding " as the main barrier.

The present paper presents some limitations, and the reduced sample is the most significant. The final number of respondents $(n=125)$ presented with a sampling error of $9 \%$. The response rate was $3.65 \%$, which is similar to the response rate presented by Nitschke et al. ${ }^{29}$. The online questionnaires were submitted in accordance with resolution 03/2014 of the Brazilian Federal Council of Dentistry, which regulates the use of Brazilian dentists' personal data for research purposes. It determines that the council itself submits the questionnaires to the professionals of the requested region. This way, the researcher does not have access to subjects' contact information, and thus could not perform follow up calls. Moreira et al. ${ }^{21}$ emphasized that the high rate of responses achieved by them was due to follow up calls by phone and researcher visits to the dentists' workplaces.

However, despite the limitations, this study is the first to our knowledge, to assess the perceptions and barriers to delivering oral health care for dependent elderly patients in unconventional settings as reported by dentists in the State of São Paulo, Brazil. As such, it may be a starting point for future research, and for guiding dental education and public health initiatives aimed at improving the oral health care workforce, and consequently the oral health of this population.

In sum, only a small proportion of the respondents provided oral health care to the dependent elderly at home, long-term care institutions or hospitals. Not having experience and/or training was the main reported barrier to providing such care and low demand was the main reason to discontinue the provision of oral health care for the dependent elderly. Experience and training, personal satisfaction, infrastructure and availability of equipment and materials at the location of care were important factors considered by all groups in the decision to provide care for the dependent elderly. All groups agreed that having gerodontology as a stand-alone course during dental school had a positive influence on their decision to provide oral health care for the dependent elderly.

In conclusion, few respondents offered care to the elderly and some of the most relevant factors considered in the decision to offer care were, experience and training, personal satisfaction and having gerodontology as a stand-alone course during dental school.

\section{Acknowledgments}

The authors would like to thank Alexandra Chamberlain for proofreading this document. 


\section{References}

1. Brazilian Institute of Geography and Statistics. [Technical note. Estimates of the population of the brazilian municipalities reference on july 1, 2014] [cited 2016 Dec 13]; Available from: URL:

2. São Paulo State. Statistics Portal of the State São Paulo [Internet]. Population projections - SSPP. [cited 2016 Aug 16]. Available from: http://produtos.seade.gov.br/produtos/projpop/index.php.

3. Grossmann Y, Nissan J, Levin L. Clinical effectiveness of implant-supported removable partial dentures: a review of the literature and retrospective case evaluation. J Oral Maxillofac Surg. 2009 Sep;67(9):1941-6. doi: 10.1016/j.joms.2009.04.081.

4. Moreira RS, Nico LC, Tomita NE. Oral health conditions among the elderly in southeastern São Paulo state. J Appl Oral Sci. 2009 May-Jun;17(3):170-8.

5. Ahluwalia KP, Cheng B, Josephs PK, Lalla E, Lamster IB. Oral disease experience of older adults seeking oral health services. Gerodontology. 2010 Jun;27(2):96-103. doi: 10.1111/j.1741-2358.2009.00311.x.

6. Bortolini S, Natali A, Franchi M, Coggiola A, Consolo U. Implant-retained removable partial dentures: an 8-year retrospective study. J Prosthodont. 2011 Apr;20(3):168-72. doi: 10.1111/j.1532-849X.2011.00700.x.

7. Chowdhry N, Aleksejuniene J, Wyatt C, Bryant R. Dentists' perceptions of providing care in long-term care facilities. J Can Dent Assoc. 2011;77:b21.

8. Preshaw PM, Walls AW, Jakubovics NS, Moynihan PJ, Jepson NJ, Loewy Z. Association of removable partial denture use with oral and systemic health. J Dent. 2011 Nov;39(11):711-9. doi: 10.1016/j.jdent.2011.08.018

9. Aida J, Katsunori K, Hiroshi H, Nakade M, Yamamoto T, Hanibuchi T, et al. Association Between Dental Status and Incident Disability in an Older Japanese Population. J Am Geriatr Soc. 2012 Feb;60(2):338-43. doi: 10.1111/j.1532-5415.2011.03791.x.

10. Matthews DC, Clovis JB, Brillant MG, Filiaggi MJ, McNally ME, Kotzer RD, et al. Oral health status of long-term care residents-a vulnerable population. J Can Dent Assoc. 2012;78:c3.

11. Gluzman R, Meeker H, Agarwal P, Patel S, Gluck G, Espinoza L, et al. Oral health status and needs of homebound elderly in an urban home-based primary care service. Spec Care Dentist. 2013 Sep-Oct;33(5):218-26. doi: 10.1111/j.1754-4505.2012.00316.x.

12. de Oliveira TC, da Silva DA, Leite de Freitas YN, da Silva RL, Pegado CP, de Lima KC. Socio-demographic factors and oral health conditions in the elderly: a population-based study. Arch Gerontol Geriatr. 2013 Nov-Dec;57(3):389-97. doi: 10.1016/j.archger.2013.05.004.

13. Sá IPC, Almeida Jr LR, Corvino MPF, Sá SPC. [Oral health conditions of the elderly in the Lar Samaritano long-term care facility in São Gonçalo - RJ]. Cienc Saude Colet. 2012 May;17(5):1259-65. doi: 10.1590/S1413-81232012000500019. Portuguese.

14. van der Putten GJ, de Visschere L, van der Maarel-Wierink C, Vanobbergen J, Schols J. The importance of oral health in (frail) elderly people - a review. Eur Geriat Med. 2013;4:339-44. doi: 10.1016/j.eurger.2013.07.007.

15. Amerine $\mathrm{C}$, Boyd L, Bowen DM, Neill K, Johnson T, Peterson T. Oral health champions in long-term care facilities-a pilot study. Spec Care Dentist. 2014 Jul-Aug;34(4):164-70. doi: 10.1111/scd.12048.

16. Bots-VantSpijker PC, Vanobbergen JN, Schols JM, Schaub RM, Bots CP, de Baat C. Barriers of delivering oral health care to older people experienced by dentists: a systematic literature review. Community Dent Oral Epidemiol. 2014 Apr;42(2):113-21. doi: 10.1111/cdoe.12068.

17. Tsakos G, Watt RG, Rouxel PL, de Oliveira C, Demakakos P. Tooth loss associated with physical and cognitive decline in older adults. J Am Geriatr Soc. 2015 Jan;63(1):91-9. doi: 10.1111/jgs.13190. 
18. Bots-VantSpijker PC, Bruers JJ, Bots CP, Vannobergen JN, de Visschere L, de Baat C, et al. Opinions of dentists on the barriers in providing oral health care to community-dwelling frail older people: a questionnaire survey. Gerodontology. 2016 Jun;33(2):268-74. doi: 10.1111/ger.12155.

19. Petersen PE. World Health Organization. The World Oral Health Report 2003. Geneva: World Health Organization; 2003 [cited 2018 Feb 15]. Available from: http://www.who.int/oral_health/media/en/ orh_report03_en.pdf.

20. Razak PA, Richard KM, Thankachan RP, Hafiz KA, Kumar KN, Sameer KM. Geriatric oral health: a review article. J Int Oral Health. 2014 Nov-Dec;6(6):110-6.

21. Moreira AN, Rocha ES, Popoff DAV, Vilaça EL, Castilho LS, de Magalhães CS. Knowledge and attitudes of dentists regarding ageing and the elderly. Gerodontology. 2012 Jun;29(2):e624-31. doi: 10.1111/j.1741-2358.2011.00534.x.

22. Watkins C, Ettinger RL, Cowen H, Qian F, Dawson DV. lowa dentists' involvement in care for patients who are homebound. Spec Care Dentist. 2012 Nov-Dec;32(6):251-8. doi: 10.1111/j.1754-4505.2012.00281.x.

23. Silva AER, Langlois COI, Feldens CA. Use of dental services and associated factors among elderly in southern Brazil. Rev Bras Epidemiol. 2013 Dec;16(4):1005-16.

24. Kiyak HA, Reichmuth M. Barriers to and enablers of older adults' use of dental services. J Dent Educ. $2005 \operatorname{Sep} ; 69(9): 975-86$.

25. Panchbhai AS. Oral health care needs in the dependant elderly in India. Indian J Palliat Care. 2012 Jan;18(1):19-26. doi: 10.4103/0973-1075.97344.

26. Stevens A, Crealey GE, Murray AM. Provision of domiciliary dental care in North and West Belfast. Prim Dent Care. 2008 Jul;15(3):105-11.

27. Sweeney MP, Manton S, Kennedy C, Macpherson LM, Turner S. Provision of domiciliary dental care by Scottish dentists: a national survey. Br Dent J. 2007 May;202(9):E23.

28. Hally J, Clarkson JE, Newton JP. Continuing dental care for Highlands elderly: current practice and attitudes of dental practitioners and home supervisors. Gerodontology. 2003 Dec;20(2):88-94.

29. Nitschke I, Ilgner A, Muller F. Barriers to provision of dental care in long-term care facilities: the confrontation with ageing and death. Gerodontology. 2005 Sep;22(3):123-9. 